\title{
Anti-flooding cathode catalyst layer for high performance PEM fuel cell
}

\author{
Aidan Li, Siew Hwa Chan*, Nam-trung Nguyen \\ School of Mechanical and Aerospace Engineering, Nanyang Technological University, \\ 50 Nanyang Avenue, Singapore 639798, Singapore \\ *Corresponding author: mshchan@ntu.edu.sg \\ Tel: 67906957, Fax: 67954634
}

\begin{abstract}
Water management in cathode catalyst layer (CCL) plays an important role in the PEM fuel cell operation. A novel anti-flooding CCL is developed with the addition of oxygen permeable and hydrophobic dimethyl silicone oil (DSO) into the catalyst layer (CL) to improve the water balance and oxygen transport within the cathode. With the addition of $0.5 \mathrm{mg} / \mathrm{cm}^{2}$ DSO in the CCL, the ability of water management has been enhanced greatly compared to that with a normal cathode. Electrochemical impedance spectroscopy has been employed to characterize the electrochemical behavior of the single fuel cell. The results show that the increased hydrophobicity of the CCL by DSO modification effectively expels water out of the voids of CCL and facilitates the water back diffusion so as to reduce the resistance of the membrane. In addition, DSO in the CCL enhances oxygen accessibility to the CCL, thus improving the performance of the PEM fuel cell significantly.
\end{abstract}

Keywords: polymer electrolyte fuel cell; cathode catalyst layer; water management; flooding; hydrophobicity; dimethyl silicone oil 


\section{Introduction}

One of the critical issues associated with the high-power PEMFCs is in water management, which needs a delicate water balance scheme between the membrane hydration and cathode flooding. On one hand, water is essential for ionomer membrane to facilitate proton conductibility [1, 2]. On the other hand, if excessive water fills the pores of the catalyst layer (CL) and gas diffusion layer (GDL), the electrode reaction becomes mass-transport-limiting, which leads to rapid cell voltage drop and immediate cell performance degradation. In view of the fact that water is produced by the oxygen reduction reaction within the CCL and transports from anode to cathode through electro-osmotic drag, proper flooding prevention in the cathode design and operation is vital in ensuring the high performance and prolonged life span of PEM fuel cells. During the operation, the properties of CCL and GDL significantly affect the balance of water in the PEM fuel cell. Sinha et al. investigated the profound influence of the underlying structure and surface wettability on liquid water transport and interfacial dynamics in the fuel cell GDL at the pore-level [3] . The micro-porous layer (MPL), placed between CL and GDL, can provide support for catalyst ink from dropping into GDL, minimize the electric contact resistance and provide wicking of liquid water into GDL to reduce mass transport limitation [4$11]$.

Although the importance of GDL in preventing flooding has been extensively studied, the role of the CCL in fuel cell water balance has never been investigated in depth, either experimentally or numerically. Most cell and stack model treat CCL as infinitesimally thin interface without structural resolution when dealing with the flooding problem because of the complexity of CCL [12]. The structure-based model revealed that CCL is the critical fuel cell component in view of excessive flooding that could give rise to limiting current behavior. The CCL can act as watershed in fuel cell to regulate the balance between the liquid water and vapor. Jiao and Zhou numerically showed that the different wettability in both CCL and GDL could affect liquid water flow patterns significantly, thus influencing the performance of the cell [13]. Magnetic particles were deposited in the CL of a cathode and magnetized to improve the performance of a PEM fuel cell in the current limited region by decreasing the saturation level of liquid water [14]. 
It was analyzed that implementing cathode modified by oxygen permeable but water immiscible perfluorocarbons would divert the water flow from CCL to PEM $[15,16]$. The objective of this study is placed on experimentally developing a novel anti-flooding cathode with the addition of oxygen permeable and hydrophobic dimethyl silicone oil (DSO) into the CCL to improve the water management and oxygen transport within the cathode. The anti-flooding property of the novel cathode is so effective that no MPL is needed in the cathode. A high performance PEM fuel cell with improved stability has been demonstrated successfully at room temperature with the novel anti-flooding cathode.

\section{Experimental}

Both anode and cathode are consisted of a wet proofed carbon paper as the backing layer and a CL. Commercial TGP-H-090 carbon papers were impregnated with 15\% PTFE to make it hydrophobic. DSO (Shin-Etsu, Japan) was emulsified into a mixture of water and isopropanol by a highly intensive ultrasonic machine (Vcx 750, Sonics, USA) with appropriate loading. Then, the catalyst ink was prepared by ultrasonically dispersing carbon-supported $50 \mathrm{wt}$ \% Pt (Johnson Matthey) catalyst and Nafion solution into the emulsion. The ink was directly spread onto the PTFE-impregnated carbon paper by using a knife-blade. The optimal DSO loading was found to be $0.5 \mathrm{mg} / \mathrm{cm}^{2}$ in this study. To better understand the effect of DSO on cathodic water management, no MPL was fabricated. The loading of Pt in the CL with and without DSO was $0.35 \mathrm{mg} / \mathrm{cm}^{2}$ with a Nafion loading of $0.56 \mathrm{mg} / \mathrm{cm}^{2}$. A pair of the anode and cathode was hot pressed on both sides of commercial Nafion 112 membrane (EW1100, DuPont) for 2 min at 135 ${ }^{\circ} \mathrm{C}$ with a pressure of $50 \mathrm{~kg} / \mathrm{cm}^{2}$ to make the membrane-electrode-assembly (MEA).

A single cell, with approximately $4 \mathrm{~cm}^{2}$ geometric electrode area and serpentine flow field, was used in the evaluation of the anti-flooding cathode performance. The steady-state polarization and electrochemical impedance spectra (EIS) were measured using Solartron Electrochemical Interface (1255B) in conjunction with a Solartron Frequency Response Analyzer (1287). Impedance spectra were recorded at frequencies range between $0.01 \mathrm{~Hz}$ and $10 \mathrm{kHz}$. Wet hydrogen (humidified at $22^{\circ} \mathrm{C}$ ) and dry air $/ \mathrm{O}_{2}$ were fed into the anode and cathode, respectively, under conditioned at a stoichiometry of 2.1 calculated at $1 \mathrm{~A} / \mathrm{cm}^{2}$. All testing was carried out at 
room temperature of around $22^{\circ} \mathrm{C}$ and atmosphere pressure.

\section{Results and discussion}

The effect of DSO on the cathode flooding and polarization behaviors is compared in Fig. 1. For the first sweep of testing, the CLs and the membrane were under dry condition which would lead to sluggish reaction in the kinetic regime as shown in the polarization curves (Fig. 1a). During the first sweeping, the fuel cell with normal cathode showed a limiting current density of 850 $\mathrm{mA} / \mathrm{cm}^{2}$, which significantly dropped to $\sim 320 \mathrm{~mA} / \mathrm{cm}^{2}$ after further polarization at a constant potential of $0.4 \mathrm{~V}$ for $3 \mathrm{hrs}$. As a contrast, under the same operating conditions, the fuel cell with DSO loaded cathode did not show limiting currents when the current densities approached to $1000 \mathrm{~mA} / \mathrm{cm}^{2}$ for both the first sweep and after 3 hrs polarization. Fig. 1b summarizes and compares the maximum power densities of the fuel cell with normal cathode and DSO loaded cathode. Similar maximum power densities of $269 \mathrm{~mW} / \mathrm{cm}^{2}$ and $255 \mathrm{~mW} / \mathrm{cm}^{2}$ were obtained for the fuel cell with normal cathode and DSO loaded cathode for the first sweep, respectively. However, after 3 hrs polarization, the maximum power density dropped to $144 \mathrm{~mW} / \mathrm{cm}^{2}$ for the fuel cell with normal cathode, whereas it increased to $356 \mathrm{~mW} / \mathrm{cm}^{2}$ for the fuel cell with DSO loaded cathode. The performance deterioration of the fuel cell with normal cathode was attributed to the diminished oxygen supply caused by the cathode flooding. The retention of bulk liquid water in the normal cathode could easily prevent the oxygen transport from entering the CCL, leading to a lower limiting current density [17]. The DSO increases the hydrophobicity of the surface of the CCL which is believed to help expel water from the voids of CCL and facilitates the hydration of PEM. Moreover, both fuel cells were found to have similar kinetic regimes (e.g. in the region where current density is less than $100 \mathrm{~mA} / \mathrm{cm}^{2}$ ), indicating that the addition of DSO in the cathode did not change the oxygen reduction behavior in the cathode.

Fig. 2 shows the impedance spectra measured at different potentials for both PEMFCs made of cathode with and without DSO after 3 hrs polarization. At high potential of $0.8 \mathrm{~V}$ (e.g. under low overpotential condition, Fig. 2a), both Nyquist plots presented a complete depressed semicircle, which is the kinetic loop. Although the diameter for these two loops were almost the same, the starting point for the cell with DSO loaded cathode was shifted to the left side, which 
means its ohmic resistance of the membrane is less than that of the fuel cell with normal cathode. This phenomenon could be explained by the increased back diffusion of product water to the membrane caused by the more hydrophobic CCL in the DSO loaded cathode. The rate of water transport from cathode to anode by back-diffusion plays an important role in PEM fuel cell performance, especially in room temperature, where saturation vapor pressure of water is extremely low. At intermediate potential, the produced water gradually turned the membrane into saturation condition. As can be seen in Fig. 2b, there was almost no difference in the ohmic resistance between the two PEMFCs with and without DSO loaded cathode. But the arc for the fuel cell without DSO cathode began to distort at such potential due to excessive water in the cathode $[18,19]$. When the fuel cell was operated at a low potential of $0.4 \mathrm{~V}$, the mass transport resistance of the fuel cell with normal cathode was around three times larger than that of the fuel cell with DSO loaded cathode.

The stability of the PEMFC with DSO loaded cathode was evaluated at output potential of $0.4 \mathrm{~V}$ at which the fuel cell reached its maximum power density with dry air as the oxidant. As shown in Fig. 3, it was surprising that even at room temperature the PEMFC with DSO loaded cathode could stably operate at $0.4 \mathrm{~V}$ with output current density of around $800 \mathrm{~mA} / \mathrm{cm}^{2}$ for more than 20 hours. Polarization behaviors of the PEMFCs with and without DSO loaded cathode were also investigated using oxygen as the oxidant at room temperature (Fig. 4). A significant improvement in the limiting current density was found for the fuel cell with DSO loaded cathode. The limiting current densities for the two fuel cells with and without DSO loaded cathode were $2000 \mathrm{~mA} / \mathrm{cm}^{2}$ and $1200 \mathrm{~mA} / \mathrm{cm}^{2}$, respectively. The maximum power density of the fuel cell with DSO cathode achieved $708 \mathrm{~mW} / \mathrm{cm}^{2}$, which was much higher than $400 \mathrm{~mW} / \mathrm{cm}^{2}$ of the fuel cell with normal cathode.

\section{Conclusions}

A novel anti-flooding cathode with addition of DSO in the cathode catalyst layer (CCL) was fabricated and evaluated in dry air and $\mathrm{O}_{2}$. The PEMFC with the novel cathode exhibited much higher performance compared to that with the normal cathode. More specifically, PEMFC without DSO loaded cathode only reached the maximum power density of $144 \mathrm{~mW} / \mathrm{cm}^{2}$ and 400 
$\mathrm{mW} / \mathrm{cm}^{2}$ in humidified hydrogen/dry air and humidified hydrogen/dry $\mathrm{O}_{2}$ system, respectively. However, under the same conditions, PEMFC with DSO loaded cathode reached the maximum power density of $356 \mathrm{~mW} / \mathrm{cm}^{2}$ and $708 \mathrm{~mW} / \mathrm{cm}^{2}$ respectively. The impedance results indicated that the substantial improvement in fuel cell performance with the DSO loaded cathode could be attributed to the increased hydrophobicity of the cathode catalyst layer which helps to expel water out of the voids in catalyst layer. 


\section{References}

[1] J. M. Le Canut, R. M. Abouatallah and D. A. Harrington, J. Electrochem. Soc. 153 (2006) A538.

[2] M. Han, S. H. Chan and S. P. Jiang, J. Power Sources 159 (2006) 1005.

[3] P. K. Sinha, P. P. Mukherjee and C. Y. Wang, Journal of Materials Chemistry 17 (2007) 3089.

[4] A. Z. Weber and J. Newman, J. Electrochem. Soc. 152 (2005) A677.

[5] H. K. Atiyeh, K. Karan, B. Peppley, A. Phoenix, E. Halliop and J. Pharoah, J. Power Sources 170 (2007) 111.

[6] X. Wang, H. Zhang, J. Zhang, H. Xu, X. Zhu, J. Chen and B. Yi, J. Power Sources, 162 (2006) 474.

[7] K. Karan, H. Atiyeh, A. Phoenix, E. Halliop, J. Pharoah and B. Peppley, Electrochem. SolidState Lett. 10 (2007) B34.

[8] Z. Qi and A. Kaufman, J. of Power Sources 109 (2002) 38.

[9] V. A. Paganin, E. A. Ticianelli and E. R. Gonzalez, J. Appl. Electrochem. 26 (1996) 297.

[10] S. Park, J. W. Lee and B. N. Popov, J. Power Sources 177 (2008) 457.

[11] C. Lim and C. Y. Wang, Electrochim. Acta 49 (2004) 4149.

[12] M. Eikerling, J. Electrochem. Soc. 153 (2006) E58.

[13] K. Jiao and B. Zhou, J. Power Sources 175 (2008) 106.

[14] L. B. Wang, N. I. Wakayama and T. Okada, Electrochem. Commun. 4 (2002) 584.

[15] S. A. Grot, US patent 6740445 (2003).

[16] A. Kraytsberg and Y. Ein-Eli, J. Power Sources 160 (2006) 194.

[17] H. Li, Y. Tang, Z. Wang, Z. Shi, S. Wu, D. Song, J. Zhang, K. Fatih, J. Zhang, H. Wang, Z. Liu, R. Abouatallah and A. Mazza, J. Power Sources 178 (2008) 103.

[18] X. Yuan, J. C. Sun, M. Blanco, H. Wang, J. Zhang and D. P. Wilkinson, J. Power Sources 161 (2006) 920. 
[19] I. A. Schneider, D. Kramer, A. Wokaun and G. G. Scherer, Electrochem. Commun. 7 (2005) 1393. 


\section{Captions of Figures:}

Fig.1 Polarization V-I curves for the first sweep of testing and after polarization at a constant potential of $0.4 \mathrm{~V}$ for 3 hours of the fuel cells with normal cathode and DSO loaded cathode (a), corresponding maximum power densities (b) in humidified hydrogen and dry air at room temperature and atmosphere pressure.

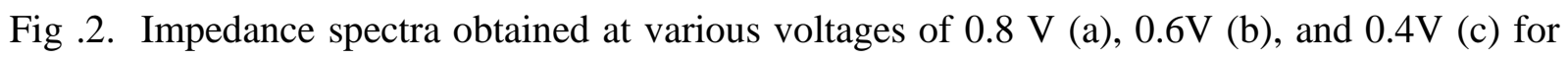
the fuel cells with normal cathode and DSO loaded cathode.

Fig. 3. Continuous performance at a constant voltage of $0.4 \mathrm{~V}$ of the fuel cell with DSO loaded cathode in humidified hydrogen and dry air at room temperature and atmosphere pressure.

Fig. 4. Polarization V-I curves and power densities of the PEMFCs with normal cathode and DSO loaded cathode in humidified hydrogen and dry oxygen at room temperature and atmosphere pressure. 

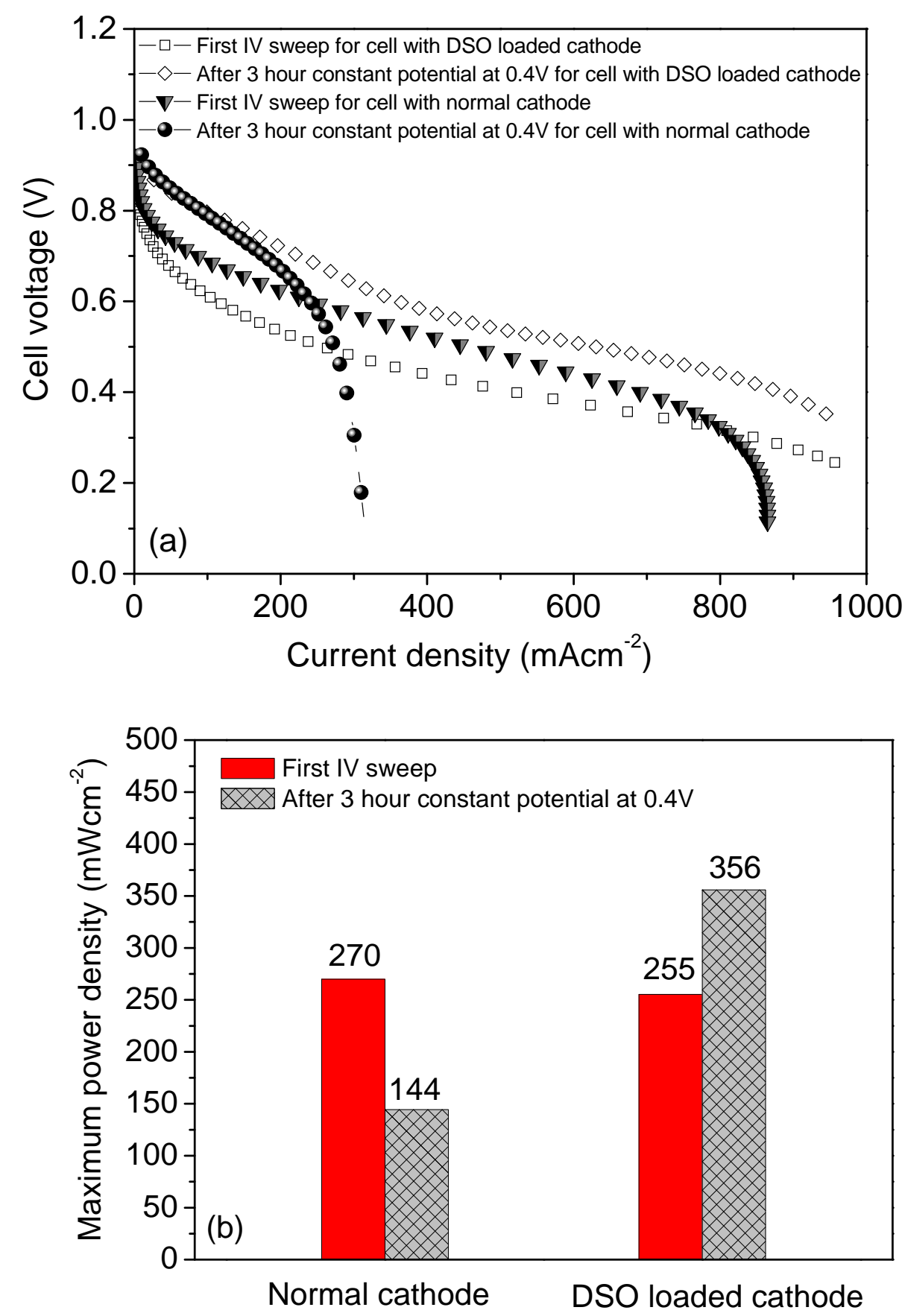

Fig. 1. 

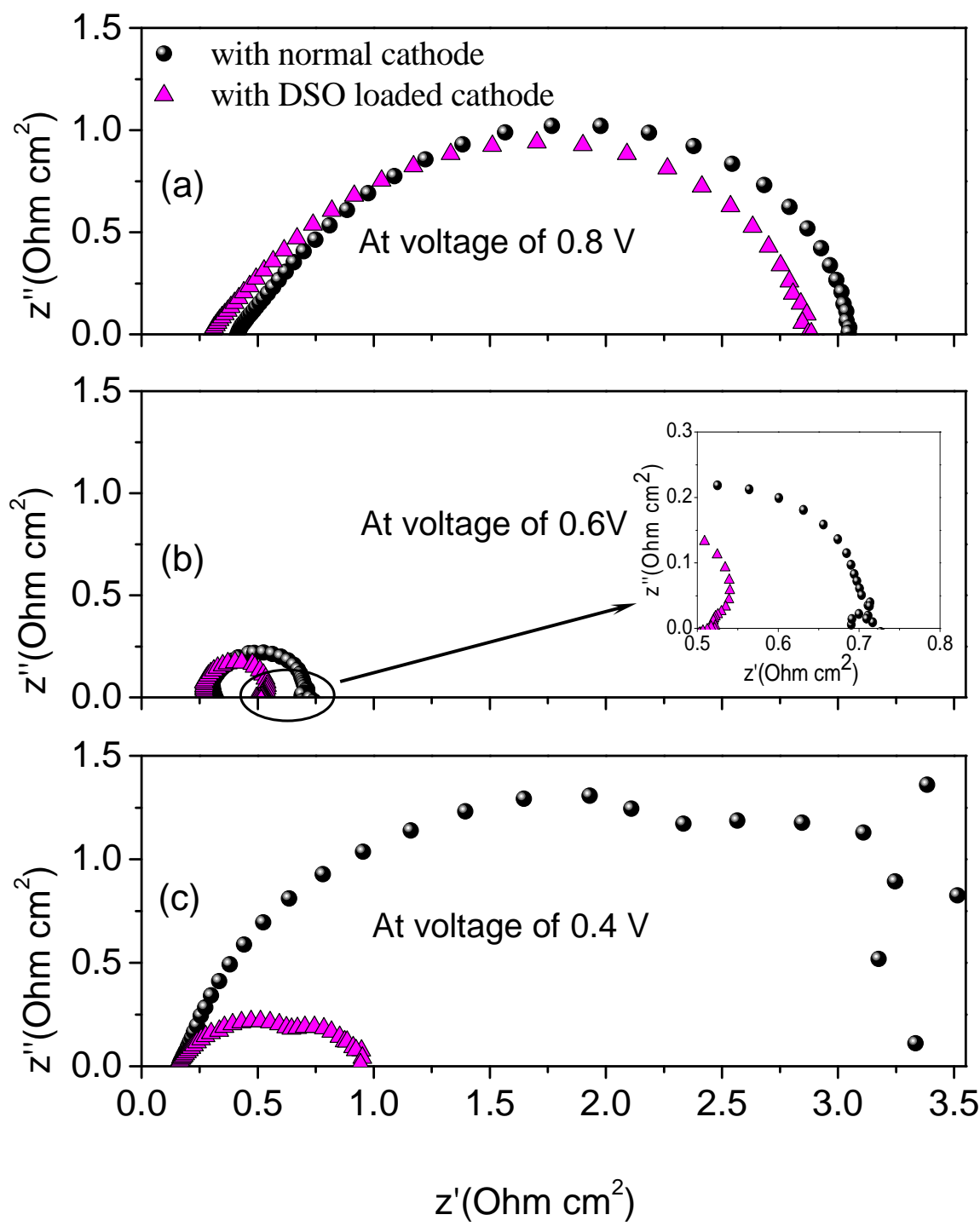

Fig. 2. 


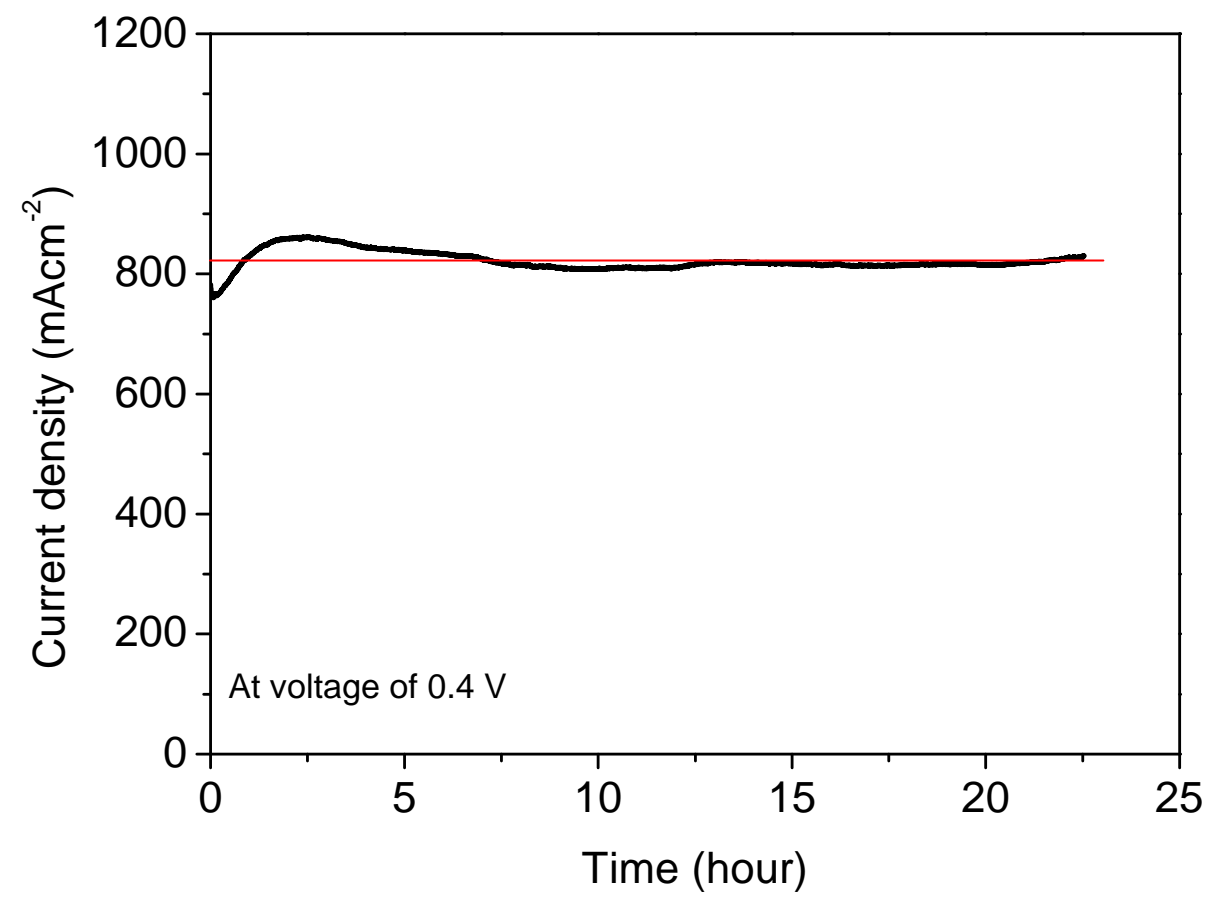

Fig. 3. 


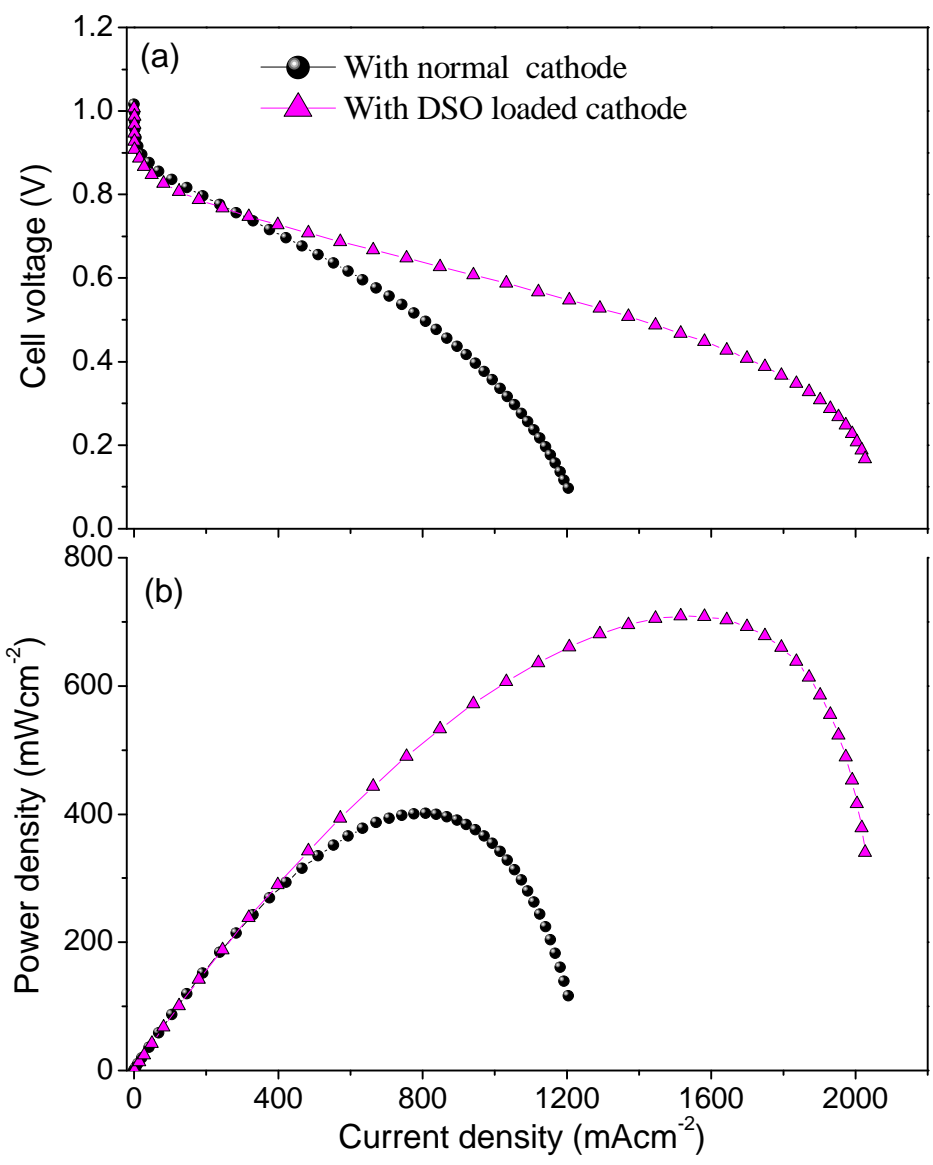

Fig. 4. 